\title{
Heat-Damage Assessment of Carbon-Fiber-Reinforced Polymer Composites by Diffuse Reflectance Infrared Spectroscopy
}

\author{
I. H. Dara, ${ }^{1}$ A. Ankara, ${ }^{2}$ G. Akovali, ${ }^{3}$ S. Suzer ${ }^{4}$ \\ ${ }^{1}$ Polymer Science and Technology Department, Middle East Technical University, 06530 Ankara, Turkey \\ ${ }^{2}$ Department of Metallurgical and Materials Engineering, Middle East Technical University, 06530 Ankara, Turkey \\ ${ }^{3}$ Department of Chemistry, Middle East Technical University, 06530 Ankara, Turkey \\ ${ }^{4}$ Department of Chemistry, Bilkent University, 06800 Ankara, Turkey
}

Received 21 January 2004; accepted 3 August 2004

DOI 10.1002/app.21500

Published online in Wiley InterScience (www.interscience.wiley.com).

\begin{abstract}
Diffuse reflectance infrared Fourier transform (DRIFT) spectroscopy was used to assess the effects of heat damage on carbon-fiber-reinforced polymer composites. Moisture-saturated graphite-epoxy laminates with a quasi-isotropic lay-up were heat-damaged above their upper service temperatures. The loss of matrix-dominated mechanical properties due to heat exposure was investigated in the laboratory under environmental testing conditions with mechanical tests, ultrasonic C-scanning, and DRIFT spectroscopy. The reduction of the mechanical strength of the composite materials was accompanied by an increase in the
\end{abstract}

carbonyl band integral and a decrease in the phenyl ratio and hydroxyl and hydrocarbon band integrals, as shown by the DRIFT spectra. DRIFT was confirmed to be more effective than ultrasonic inspection in evaluating the extent of heat damage, and a good correlation was found between the mechanical test results and DRIFT spectra. (c) 2005 Wiley Periodicals, Inc. J Appl Polym Sci 96: 1222-1230, 2005

Key words: composites; degradation; infrared spectroscopy; mechanical properties; resins

\section{INTRODUCTION}

A high strength-to-weight ratio, a good stiffness-todensity ratio, high dimensional stability, and good corrosion resistance are the most important features of high-performance carbon-fiber-reinforced polymer (CFRP) composite components, which are extensively used in the aerospace industry. In the last 2 decades, the safety and reliability of these materials have gained more importance with their increased utilization. The tendency of carbon-epoxy composites to become irreversibly damaged because of exposure to elevated temperatures is of particular interest in the aerospace industry; therefore, the characterization of such heat damage in CFRP composite structural components has attracted considerable attention.

The upper service temperature for most epoxy resin composites has been reported to be $140^{\circ} \mathrm{C}$. High-temperature exposure above this may cause heat damage resulting in a severe loss of mechanical properties of the composite structure. The resin properties are a

Correspondence to: S. Suzer (suzer@fen.bilkent.edu.tr).

Contract grant sponsor: North Atlantic Treaty Organization-Applied Vehicle Technology Panel (NATO-AVT); contract grant number: T-123.

Journal of Applied Polymer Science, Vol. 96, 1222-1230 (2005) (c) 2005 Wiley Periodicals, Inc. primary concern in the assessment of the heat damage of CFRP components, as thermal degradation is matrix-dominated. ${ }^{1,2}$ High-temperature exposure leads to resin degradation, which is associated with a drop in the glass-transition temperature, which reduces the mechanical strength of the composite. Surface embrittlement and cracking lead to a loss of impact strength, and this may finally lead to irreversible and catastrophic failure. $^{3}$

The heat damage of CFRP components of aerospace structures may be due to handling mishaps, accidents (fires, etc.), lightening strikes, or ground-reflected engine efflux from landing aircraft. When a component is exposed to overheating locally, shriveling and blisters may occur on the surface, and the internal delaminations resulting from them may be examined by nondestructive inspection (NDI) techniques. However, there is no technology available yet to discriminate undamaged sections of graphite-epoxy laminates from damaged section of the laminates if the damage cannot be observed visually. Therefore, it is not practically possible to repair this type of damage with confidence. There is a crucial need for an industrial NDI method that can be readily applied to aerospace structures to provide reliable and repeatable estimations of heat-damaged zones and possible heatdamage effects on physical and mechanical properties of CFRP composite structures. ${ }^{4}$ Nondestructive exam- 
ination (NDE) techniques based on ultrasonic methods have been reported to be inadequate for detecting the extent of heat damage. ${ }^{5}$ Diffuse reflectance infrared Fourier transform (DRIFT) spectroscopy is a promising method for the evaluation and characterization of heat damage in carbon-epoxy composites because it provides the opportunity to determine the first traces of degradation reactions before considerable strength degradation takes place. ${ }^{6}$

\section{EXPERIMENTAL}

\section{Panel production and moisture saturation}

The test plates were produced by European Aircraft Defence and Space Co. (Munich, Germany) from a Hercules IM7/8552 carbon-epoxy prepreg (Denver, $\mathrm{CO})$. This prepreg is a commercially available product and is produced through the impregnation of an amine [diamino diphenyl sulfone (DDS)]-cured [tetraglycidyl methylene dianiline (TGMDA)] epoxy resin into unidirectional carbon-fiber fabric. The plates were hand-laid and cured in an autoclave according to the producer's recommended cure cycle by a conventional vacuum bag procedure. The stacking sequence was $[0 / 0 /+45 /-45 / 0 / 0 /+45 /-45 / 0]_{\text {symm }}$ for the 18-ply interlaminar shear strength (ILSS) test plates and $[+45 /-45 / 0 / 90]_{4 \text { symm }}$ for the compression strength test plates. The parent laminates were inspected by ultrasonic C-scanning for any production defects before moisture saturation. The parent laminates were then cut into test plates of various sizes for compression and interlaminar shear testing.

The epoxy resins absorb high levels of moisture under the ambient conditions because of their hydrophilic nature. Therefore, all thermal loading and mechanical testing of the specimens were carried out under a wet (moisture-saturated) condition to simulate the actual service conditions of aircraft components. Moisture conditioning was performed according to ASTM E 104 ("Standard Practice for Maintaining Constant Relative Humidity by Means of Aqueous Solutions"). The test plates were moisture-saturated in a humidity chamber in which an aqueous $\mathrm{KCl}$ solution provided $85 \%$ relative humidity at $70^{\circ} \mathrm{C}$. The absorbed moisture behaved as a plasticizer in the matrix and caused a considerable decrease in the mechanical properties of the composite. When exposed to high temperatures, the absorbed water evaporated and could be trapped in the laminate and lead to severe delamination. ${ }^{7}$ The main reason for the moisture conditioning for the test plates before thermal loading was to include moisture effects that aircraft components experience during actual service conditions.

\section{Thermal loading of the test specimens}

The moisture-saturated test panels were thermally loaded at various temperatures in a Memmert Gmbh
(Schwabach, Germany) ULM-400 air-circulating furnace with a digital control and fan system. The test plates were exposed to temperatures ranging from 190 to $250^{\circ} \mathrm{C}$ for $30 \mathrm{~min}$ from one face only in a Kaowool (Augusta, GA) insulating alumina blanket box. This type of heat exposure was chosen to simulate most of the actual heat-damage conditions likely to be experienced by aircraft components, such as a heat blast from a jet engine of a nearby aircraft maneuvering on the ground. The furnace was first heated to the desired exposure temperature, and then the test plate in the refractory box was placed inside the furnace. After the furnace was stabilized at the set temperature (this took a few minutes), the lid of the refractory box was removed to simulate sudden one-sided heat exposure. Thermocouples were placed beneath the selected test plates to confirm that the surfaces of the plates that were not exposed to heat could be kept at a low temperature during the short period in which the furnace stabilized at the preset temperature. After heat exposure, the plates were removed from the furnace and cooled to room temperature before mechanical testing. After thermal loading, the test panels were reinspected by ultrasonic C-scanning for any damage effects. Figure 1 presents C-scan images of the ILSS test plates.

\section{Mechanical testing}

The mechanical testing of test plates was performed at room temperature and a high temperature $\left(120^{\circ} \mathrm{C}\right)$ according to ASTM 695M ("Test Method for the Determination of Compression Strength and Modulus of Rigid Plastics and Fibre Reinforced Plastics") and EN 2563 ("Test Method-Determination of Interlaminar Shear Strength"). The results of these tests and the average compressive and ILSS loss values are given in Tables I and II, respectively.

\section{DRIFT spectroscopy}

DRIFT spectroscopy is a practical NDI method in which an IR light beam is scattered from the surface of a material and the diffusely scattered light is collected and converted into an IR spectrum. Qualitative and quantitative chemical information is obtained from this DRIFT spectrum. One advantage of DRIFT spectroscopy over other internal reflectance techniques is that this method of spectroscopy does not require mechanical contact with the material. ${ }^{8,9}$ A Bomem MB102 Fourier transform infrared instrument (Quebec, Canada) with a Harrick praying mantis diffuse reflectance attachment was used in this study. The spectrometer had a CsI beam splitter with a usable spectral range of $210-5000 \mathrm{~cm}^{-1}$. The DRIFT spectra were collected at a resolution of $4 \mathrm{~cm}^{-1}$ with 256 scans. Five DRIFT spectra were collected for each specimen, 


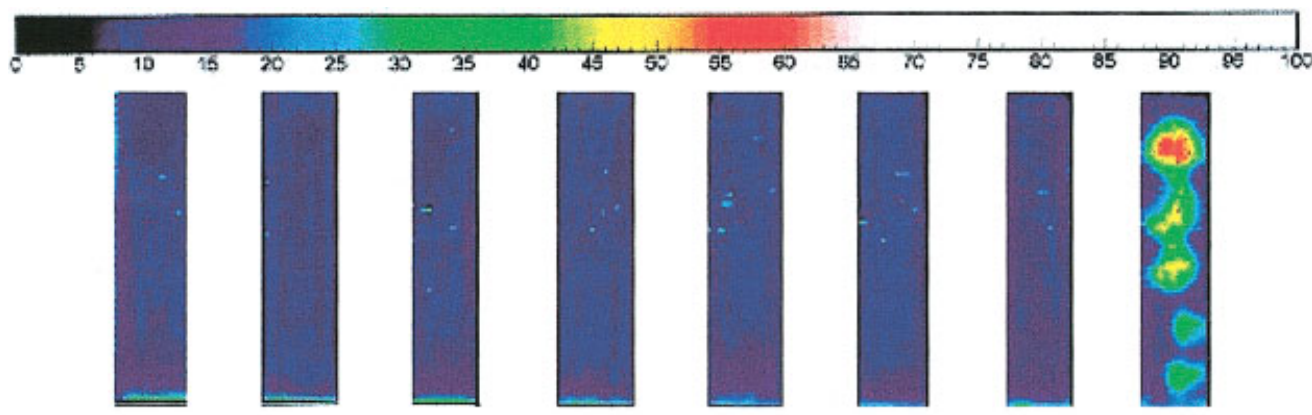

(a)

(b)

(c)

(d)

(e)

(f)

(g)

(h)

Figure 1 C-scan images of ILSS test panels thermally loaded at (a) 180, (b) 190, (c) 200, (d) 210, (e) 220, (f) 230, (g) 250, and (h) $260^{\circ} \mathrm{C}$. [Color figure can be viewed in the online issue, which is available at www.interscience.wiley.com.]

and these data were evaluated and used to quantify the ratios of the chemical moieties in the outer layer of the resin. ${ }^{10}$ Spectral data were reduced to meaningful and comparable numbers by baseline correction and normalization. The three important steps of the procedure are given in Figure 2. Peak areas were used in spectral elaboration studies. The phenyl ratio and hydrocarbon and carbonyl band integrals were calculated for further correlation with mechanical test results.

TABLE I

Compression Test Results and Compressive Strength Loss Values

\begin{tabular}{|c|c|c|c|}
\hline Specimen ID & $\begin{array}{c}\text { Exposure } \\
\text { temperature } \\
\left({ }^{\circ} \mathrm{C}\right)\end{array}$ & $\begin{array}{c}\text { Average } \\
\text { compressive } \\
\text { strength at room } \\
\text { temperature } \\
(\mathrm{MPa})\end{array}$ & $\begin{array}{c}\text { Compressive } \\
\text { strength loss } \\
(\%)\end{array}$ \\
\hline 8552-REF & - & $485.3 \pm 11.2$ & - \\
\hline $8552-220$ & 220 & $406.9 \pm 27.5$ & 16 \\
\hline $8552-230$ & 230 & $347.8 \pm 28.7$ & 29 \\
\hline $8552-250$ & 250 & $249.2 \pm 37.1$ & 49 \\
\hline $8552-260$ & 260 & $239.1 \pm 33.2$ & 51 \\
\hline
\end{tabular}

\section{RESULTS}

\section{Mechanical test results}

The compressive strength loss for the test plates thermally loaded at $260^{\circ} \mathrm{C}$ was around $50 \%$, which also increased with an increasing thermal loading temperature, as expected. However, the standard deviations were high for the compressive strength values, and so these values were used only to probe the general trends. The maximum ILSS strength loss at room temperature was around 16\% for thermally loaded test panels at $260^{\circ} \mathrm{C}$, whereas it reached up to $40 \%$ at $120^{\circ} \mathrm{C}$. The absorbed moisture resulted in a $10 \%$ ILSS loss at room temperature and a $45 \%$ loss at $120^{\circ} \mathrm{C}$. The ILSS loss at room temperature versus the thermal loading temperature is displayed at the top of Figure 3. Similar trends were also observed at $120^{\circ} \mathrm{C}$ (not shown). The ILSS loss decreased until $220^{\circ} \mathrm{C}$, after which it started to increase. The initial decrease was attributed to the probable postcure reactions taking place at this temperature, in agreement with the results of previous researchers. ${ }^{11,12}$ Visual delamination was observed for specimens thermally loaded at

TABLE II

ILSS Test Results and ILSS Loss Values

\begin{tabular}{|c|c|c|c|c|c|}
\hline Specimen ID & $\begin{array}{c}\text { Exposure } \\
\text { temperature } \\
\left({ }^{\circ} \mathrm{C}\right)\end{array}$ & $\begin{array}{c}\text { Average ILSS at room } \\
\text { temperature } \\
(\mathrm{MPa})\end{array}$ & $\begin{array}{c}\text { ILSS loss at room } \\
\text { temperature } \\
(\%)\end{array}$ & $\begin{array}{l}\text { Average ILSS } \\
\text { at } 120^{\circ} \mathrm{C} \\
(\mathrm{MPa})\end{array}$ & $\begin{array}{c}\text { ILSS loss at } \\
120^{\circ} \mathrm{C} \\
(\%)\end{array}$ \\
\hline 8552-REF & - & $85.9 \pm 2.8$ & - & $56.9 \pm 3.1$ & 33.8 \\
\hline 8552-WETREF & - & $77.8 \pm 3.6$ & 9.4 & $47.8 \pm 1.6$ & 44.3 \\
\hline $8552-180$ & 180 & $81.3 \pm 1.8$ & 5.3 & $55.8 \pm 2.6$ & 35.0 \\
\hline $8552-190$ & 190 & $81.9 \pm 2.8$ & 4.6 & $57.2 \pm 1.3$ & 32.4 \\
\hline $8552-200$ & 200 & $85.6 \pm 3.0$ & 0.3 & $58.1 \pm 1.2$ & 33.4 \\
\hline $8552-210$ & 210 & $84.1 \pm 2.1$ & 2.1 & $59.1 \pm 2.7$ & 31.2 \\
\hline $8552-210$ (as received) & 210 & $83.3 \pm 3.6$ & 3.0 & $59.9 \pm 1.8$ & 30.3 \\
\hline $8552-220$ & 220 & $80.8 \pm 3.3$ & 5.9 & $56.9 \pm 1.5$ & 33.8 \\
\hline $8552-230$ & 230 & $79.3 \pm 3.7$ & 7.7 & $57.4 \pm 1.5$ & 33.2 \\
\hline $8552-250$ & 250 & $77.8 \pm 3.5$ & 9.4 & $55.9 \pm 1.5$ & 35.0 \\
\hline $8552-260$ & 260 & $72.4 \pm 3.7$ & 15.7 & $52.5 \pm 3.4$ & 38.9 \\
\hline
\end{tabular}



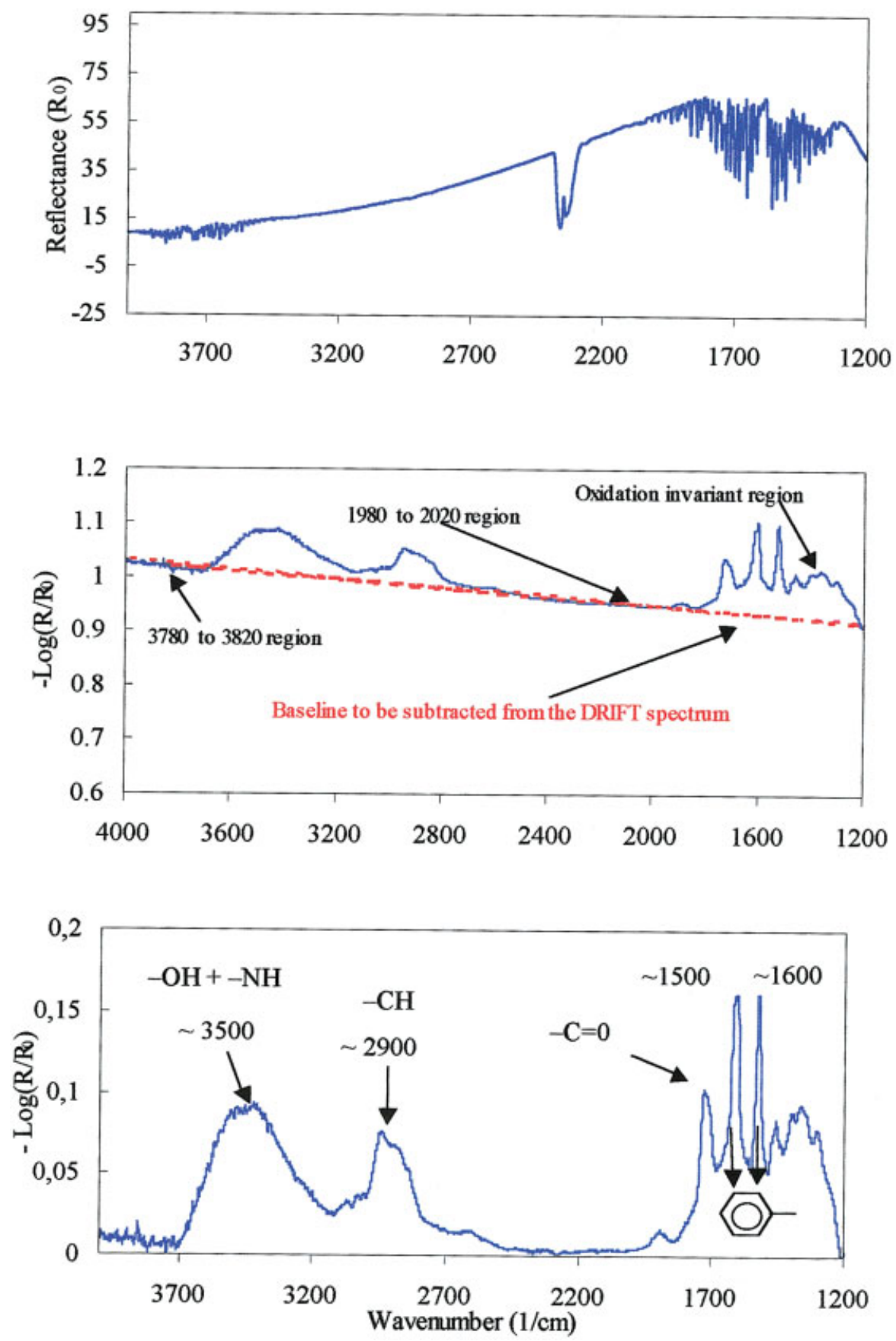

Figure 2 Steps involved in obtaining a DRIFT spectrum. In step 1 (top graph), the background spectrum is obtained from the mirror surface. In step 2 (middle graph), the background-subtracted spectrum shows the different regions. In step 3 (bottom graph), the baseline-corrected final spectrum is obtained. $R_{0}=$ the intensity of the reflected beam from the reference mirror; $\mathrm{R}=$ from the sample.

$260^{\circ} \mathrm{C}$. Therefore, the results at this temperature were not included for DRIFT correlations.

\section{DRIFT spectroscopy results}

Thermal damage is a complex process that may involve several mechanisms causing a loss of strength without oxidation of the resin due to heat exposure above the glass-transition temperature and a loss of strength due to oxidative degradation of the resin and fiber-resin interface through oxidation, hydrolysis, and dehydration reactions. ${ }^{13}$ Oxygen addition as carbonyl species, the loss of hydrocarbon and hydroxyl species, and changes in the structure of aromatic rings (in some cases) are indications of the aforementioned reactions and can be monitored with DRIFT spectra. ${ }^{14}$ 

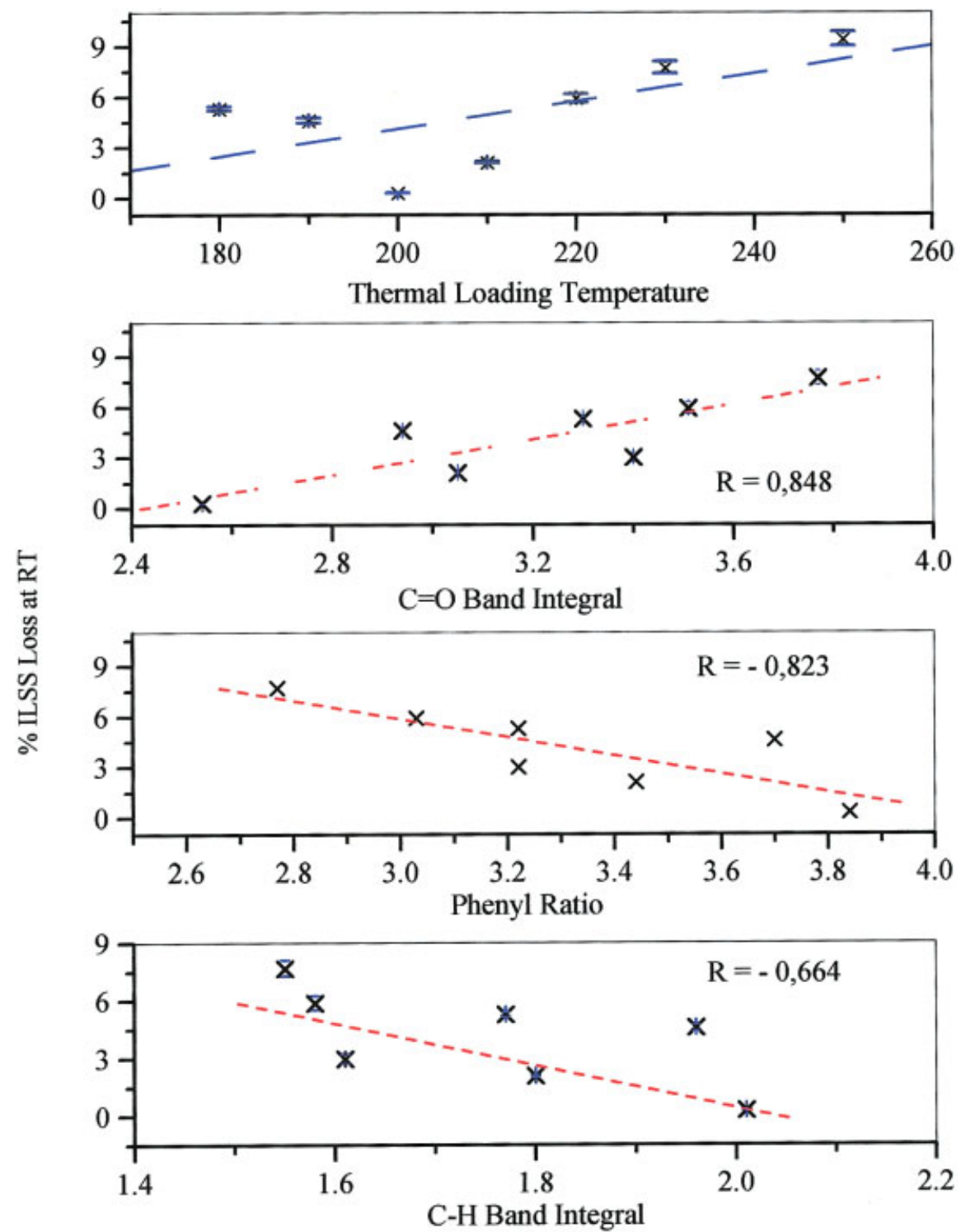

Figure 3 Variation of the ILSS loss at room temperature (RT) with the thermal loading temperature, carbonyl band integral, phenyl ratio, and hydrocarbon band integral. $\mathrm{R}=$ correlation coefficient.

DRIFT spectroscopy can detect chemical evidence of oxidation of the outer resin layer in carbon-epoxy composites. However, in a previous study ${ }^{15}$ on thermal loading effects of CFRP composites, the temperature distribution in the thickness direction of a laminate produced from the same IM7/8552 carbon-epoxy system (subjected to $200^{\circ} \mathrm{C}$ from one face) showed explicitly the rapid propagation of heat in the through-thickness direction of the laminate. This revealed that the thermal damage within the laminate was widespread and could cause delaminations between all plies and microcracking in the matrix resin. Cross verification of this result was demonstrated by a comparison of the DRIFT spectra obtained from both surfaces of a carbon-epoxy test plate thermally loaded at $220^{\circ} \mathrm{C}^{10}$ The prepreg (HMF/F263, Hexcel, Da- gneux, France) used for the production of this test plate was an epoxy resin [amine (DDS)-cured (TGMDA)] similar to the prepreg used for the production of test plates in this study. The DRIFT spectrum obtained from the surface, which was exposed to heat, overlapped the DRIFT spectrum obtained from the surface, which was not exposed to heat, with almost one-to-one correspondence, as shown in Figure 4. Therefore, we could comment on the bulk mechanical properties, using the results based on the surface chemical analysis of a laminate in a similar thickness range.

The DRIFT spectra were normalized on the basis of the broad and rather featureless region of absorption around $1350 \mathrm{~cm}^{-1}$, which was relatively unaffected by thermal damage. The spectra were scaled so that each 


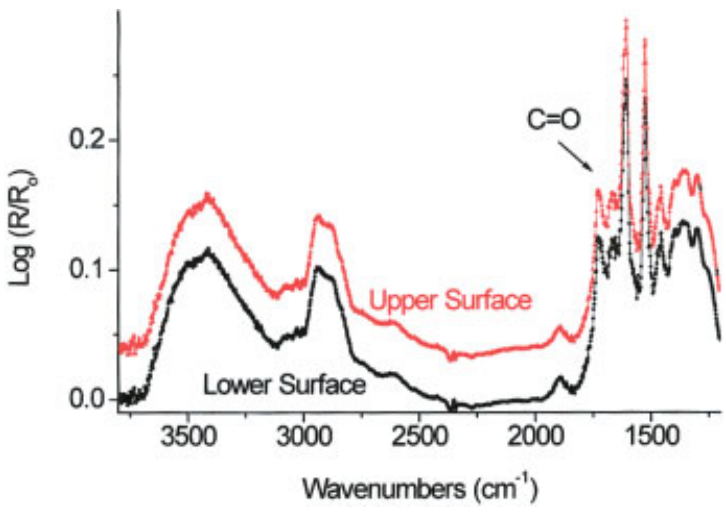

Figure 4 DRIFT spectra recorded for the heat-exposed (upper) surface and opposite (lower) surface of a sample similar to the test panels used in this work. [Color figure can be viewed in the online issue, which is available at www. interscience.wiley.com.]

had the same near nominal value at $1350 \mathrm{~cm}^{-1}$, and this value was calculated as an average of $1335-1365 \mathrm{~cm}^{-1}$ for all groups of test plates. There were two regions of the spectra to be considered: (1) the $1200-2000-\mathrm{cm}^{-1}$ region, which included the carbonyl region in which oxygen addition reactions resulted in absorption bands occurring between 1600 and $1900 \mathrm{~cm}^{-1}$, and (2) the 2000-4000- $\mathrm{cm}^{-1}$ region, which contained bands for aliphatic and aromatic hydrocarbons, amines, and hydroxyls. ${ }^{16-18}$ The term band refers to a normalized peak height. The term band integral (or area) refers to an integral over some region of the baseline-corrected spectrum divided by the integral between 1335 and $1365 \mathrm{~cm}^{-1}$; this region of the spectrum was not strongly affected by oxidation. For the carbonyl region, the integration range was $1600-1825 \mathrm{~cm}^{-1}$, whereas for the hydrocarbon region, it was $2660-3125 \mathrm{~cm}^{-1}$. The phenyl ratio was calculated by the division of the maximum and minimum of the baseline-corrected spectra between 1500 and 1550 $\mathrm{cm}^{-1}$.

Characteristic spectra are plotted in Figure 5 for the as-produced reference group and for test plates thermally loaded at $210,220,230$, and $250^{\circ} \mathrm{C}$. They exhibit the main absorption bands to be considered for this specific material.

The $\mathrm{C}=\mathrm{O}$ (carbonyl) stretch band occurring at 1660 $\mathrm{cm}^{-1}$ was primary evidence for the presence of an aldehyde or ketone. In addition, the absence of a methyl group in the spectra indicated that isomerization to an aldehyde rather than to a ketone was preferred: ${ }^{19}$

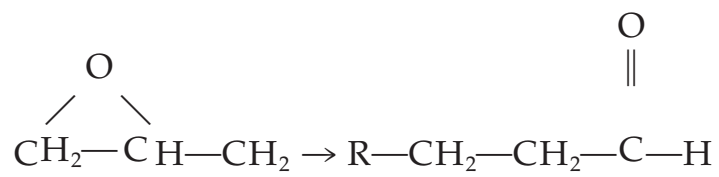

The bands occurring near 1500 and $1600 \mathrm{~cm}^{-1}$ were attributed to benzene rings of TGMDA and DDS. The shoulder at $1490 \mathrm{~cm}^{-1}$, overlapping the phenyl band $\left(1500 \mathrm{~cm}^{-1}\right)$, was most likely due to the presence of phenol originating from the para-amino phenol present in the epoxy resin content. ${ }^{16-18}$ Figure 4 shows that the intensity of the phenyl bands decreased with an increasing thermal loading temperature because of the disordering of the aromatic ring mode(s). Very powerful activating groups such as amino groups and hydroxyl groups caused the benzene ring to be so active that the structure was more susceptible to undesirable reactions such as electrophilic substitution and oxidation. The DRIFT spectra of the test plates thermally loaded at $260^{\circ} \mathrm{C}$ were discarded during calculations because these plates exhibited delamination, which could be detected visually. Therefore, the mechanical test results obtained for this temperature were considered to be unreliable. The $-\mathrm{C}=\mathrm{O}$ (carbonyl) band occurring at $1665 \mathrm{~cm}^{-1}$ was attributed to amide formation. ${ }^{16-18}$ The increase in the carbonyl band integral with an increasing thermal loading temperature was a strong indication of thermooxidative degradation. The band at $1300 \mathrm{~cm}^{-1}$ was attributed to - $\mathrm{CN}$ stretching vibrations, and the distinct band occurring at $1250 \mathrm{~cm}^{-1}$ was most likely due to the $-\mathrm{C}-\mathrm{C}$ and $-\mathrm{C}-\mathrm{C}-\mathrm{N}$ vibrations of aromatic amine groups. ${ }^{16-18}$

In the 2000-4000- $\mathrm{cm}^{-1}$ range, there were basically three bands to be considered. The rather broad band between 3300 and $3600 \mathrm{~cm}^{-1}$ probably consisted of a - OH (hydroxyl) stretching band, which is often reported between 3400 and $3500 \mathrm{~cm}^{-1}$, and $\mathrm{N}-\mathrm{H}$ stretching vibrations, which occur around 3400 $\mathrm{cm}^{-1} \cdot{ }^{16-18}$ The decrease in the $-\mathrm{OH}$ stretching vibrations was attributed to the dehydration of secondary alcohols, which were formed during the cure reactions. However, it was very difficult to distinguish between the hydroxyl and amine bands.

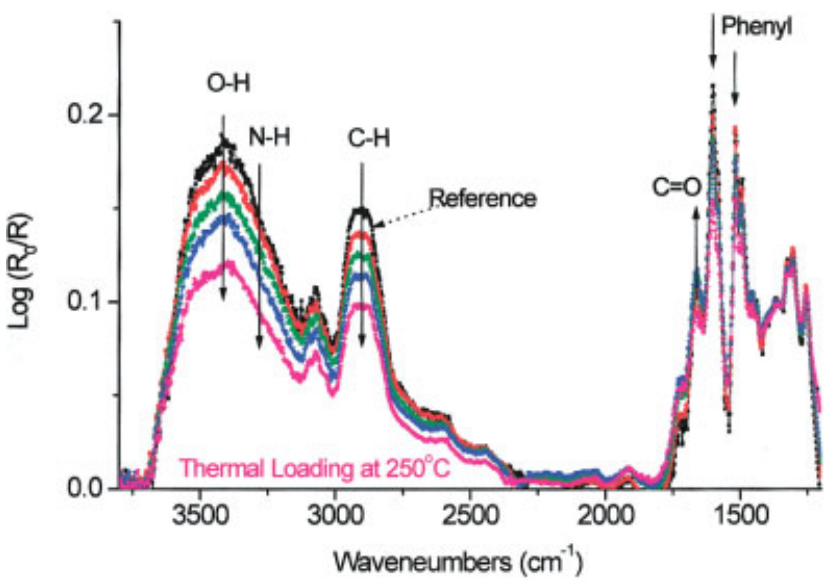

Figure 5 DRIFT spectra for reference-group (untreated) test plates and test plates thermally loaded at 210, 220, 230, and $250^{\circ} \mathrm{C}$. [Color figure can be viewed in the online issue, which is available at www.interscience.wiley.com.] 
The other two bands of concern were due to $-\mathrm{CH}$ stretching vibrations occurring around 2900 and 3075 $\mathrm{cm}^{-1}$ and belonging to aliphatic and aromatic $-\mathrm{CH}$ functional groups, respectively. ${ }^{16-18}$ Figure 4 shows that the $-\mathrm{CH}$ band intensities decreased with an increasing thermal loading temperature. This decrease was mainly due to dehydration reactions and the removal of small molecular fragments from the system due to the breaking of intermolecular and intramolecular chains. There was a gradual decrease in the $-\mathrm{CH}$ concentration with an increasing thermal loading temperature.

Accordingly, the main degradation reactions occurring during the high-temperature loading of the IM7 / 8552 carbon-epoxy system can be summarized as follows:

1. Oxidation could be monitored by the increasing $-\mathrm{C}=\mathrm{O}$ (carbonyl) band integral area, which was in good agreement with the decreasing $-\mathrm{CH}$ bands. The phenyl ratio could also be accepted as a strong indicator of oxidation, and the intensity of the phenyl peaks decreased because of a probable change in the structure of the aromatic ring,

2. Dehydration could be monitored by the decrease in the $-\mathrm{OH}$ stretching band intensities.

\section{Mechanochemical correlations}

The room-temperature and $120^{\circ} \mathrm{C}$ ILSS loss variations with the carbonyl band integral, hydrocarbon band integral, and phenyl ratio between 180 and $250^{\circ} \mathrm{C}$ are plotted in Figure 3. A similar correlation between the room-temperature compressive strength and the carbonyl band integral, hydrocarbon band integral, and phenyl ratio between 180 and $250^{\circ} \mathrm{C}$ is presented in Figure 6 . The compressive strength value of the test panels thermally loaded at $260^{\circ} \mathrm{C}$ was discarded in the evaluation because of visual delamination observed in the test specimens. The standard deviations of the compressive and ILSS values were high for this group of tests plates. The compressive strength and ILSS decreased with an increasing carbonyl band integral, a decreasing $-\mathrm{CH}$ band integral, and a decreasing phenyl ratio.

Recalling the ultrasonic C-scan test results, which could detect heat damage almost above $250^{\circ} \mathrm{C}$, we found that DRIFT was better for the assessment of incipient heat damage. The carbonyl band integral and phenyl ratio were two sensitive measures for detecting thermooxidative degradation in the DDS-cured TGMDA carbon-epoxy system in the specified temperature ranges, as also evidenced by their correlation coefficients. The trends observed for the $-\mathrm{CH}$ band integral showed that the hydrocarbon band integral was not as sensitive (a smaller correlation coefficient) as the carbonyl band integral and phenyl ratio, but it could be used to comment on the degradation reactions taking place because of thermal loading.

\section{CONCLUSIONS}

In this study, three parameters (the carbonyl band integral, hydrocarbon band integral, and phenyl ratio), deduced from DRIFT spectra, were used to comment on the thermal degradation mechanisms in the IM7/8552 carbon-epoxy system.

Thermooxidative degradation was best monitored by an increase in the carbonyl band integral and a decrease in the phenyl ratio with an increase in the thermal loading temperature. The carbonyl band integral stood out as a perfect indicator of the addition of oxygen as various carbonyl species such as amides. There was a decrease in the mechanical strength values with an increasing carbonyl band integral and a decreasing phenyl ratio, and this revealed the extent of oxidation that took place because of thermal loading.

A phenyl algorithm indicating the decrease in the intensity of the phenyl bands was also shown to be a very good indicator of thermooxidative degradation and was sensitive to the early indications of oxidation before considerable strength loss occurred. The decrease in the phenyl band intensity might have originated from the disordering of the aromatic ring structure.

The hydrocarbon band integral, though less sensitive than the carbonyl band integral and phenyl ratio, was another useful parameter for the prediction of the loss of mechanical strength. The decrease in the hydrocarbon band integral could be attributed to the oxidation reaction, the breaking of the intermolecular and intramolecular chains in the backbone, and the removal of small molecular fragments due to increased activation energy in the system via heat exposure, which resulted in degraded mechanical properties. The overlapping bands in the carbonyl region might also have originated from the double bonds occurring as a result of the dehydration reactions on the secondary alcohol groups. The decrease in the $-\mathrm{OH}$ band intensities was attributed to the dehydration reactions occurring during thermal loading.

Therefore, two separate or combined degradation reactions, oxidation and dehydration, likely took place in the IM7/8552 DDS-cured TGMDA carbon-epoxy composites during thermal loading between 190 and $260^{\circ} \mathrm{C}$.

DRIFTS was found to be more adequate in assessing incipient heat damage occurring on the molecular scale than ultrasonic nondestructive testing and to provide the possibility of commenting on degradation mechanisms, rather than making the prediction of the degradation of mechanical strength possible. Mechan- 

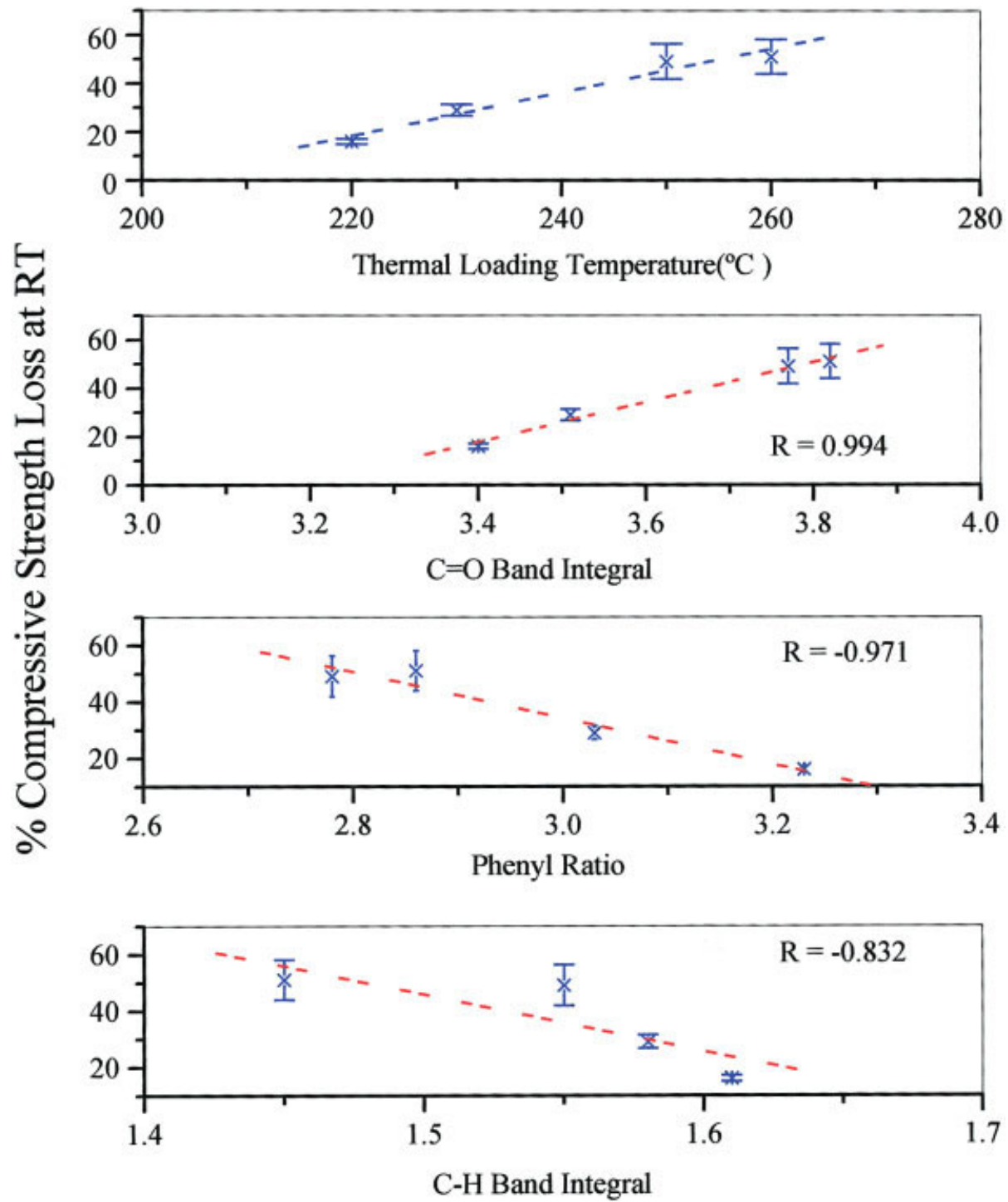

Figure 6 Variation of the compressive strength loss at room temperature (RT) with the thermal loading temperature, carbonyl band integral, phenyl ratio, and hydrocarbon band integral.

ical strength degradation can be characterized for any structural component of an aircraft by DRIFTS, and a DRIFT instrument, being handy, portable, and lightweight, has potential in situ nondestructive applications in the aircraft industry.

For establishing a better correlation between the mechanical test results and the DRIFT spectra, wider ranges of temperatures and exposure times for different graphite-epoxy systems need to be tested and reevaluated along with the results of this study.

The authors thank Besim Gokce Dara from Roketsan Missiles, Inc., for assistance and discussions. Roketsan Missiles, Inc., Turkish Aerospace Industries, and European Aircraft Defence and Space Co. (EADS) are gratefully acknowledged for materials and experimental support. The authors also thank Detlef Weisgerber from EADS Germany for guidance and valuable advice.

\section{References}

1. Patel, R. H.; Patel, R. G. Polym Int 1993, 30, 301.

2. Pering, G. A.; Farrell, P. V.; Springer, G. S. J Compos Mater 1980, 14,54 .

3. Matzkanin, G. A. Proceedings of the Conference on the Characterization and NDE of Heat Damage in Graphite Epoxy Composites, Orlando, FL; NTIAC: Austin, TX, 1993; p 9.

4. Collins, R.; Mahon, J. Proceedings of the Conference on the Characterization and NDE of Heat Damage in Graphite Epoxy Composites, Orlando, FL; NTIAC: Austin, TX, 1993; p 53.

5. Janke, C. J.; Wachter, E. A.; Philpot, H. E.; Powell, G. L. Proceedings of the Conference on the Characterization and NDE of Heat Damage in Graphite Epoxy Composites, Orlando, FL; NTIAC: Austin, TX, 1993; p 77.

6. Powell, G. L.; Symrl, N. R.; Janke, C. J.; Wachter, E. A.; Lucania, J.; Milosevic, M.; Auth, G. Proceedings of the Conference on the Characterization and NDE of Heat Damage in Graphite Epoxy Composites, Orlando, FL; NTIAC: Austin, TX, 1993; p 97.

7. Henderson, J. B.; Wiecek, T. E. J Compos Mater 1987, 21, 741. 
8. Cole, K. C.; Pilon, A.; Noel, D.; Hechler, J. J.; Chouliotis, A.; Overburry, K. C. Appl Spectrosc 1988, 42,761.

9. Mitchell, M. B. Fundamentals and Applications of Diffuse Reflectance Infrared Fourier Transform (DRIFT) Spectroscopy, Structure Property Relations in Polymers; American Chemical Society: Washington, DC, 1993; p 351.

10. Dâra, I. H. Ph.D. Thesis, Middle East Technical University, 2002.

11. Engineering Materials Handbook; ASM International: Columbus, OH, 1988; Volume 1.

12. Levy, R. L.; Fanter, D. L.; Summers, C. J. J Appl Polym Sci 1979, $24,1643$.
13. Luoma, G. A.; Rowland, R. D. J Appl Polym Sci 1986, 32, 5777.

14. Powell, L.; Janke, C. J.; Barber, T. E. Presented at the 29th International SAMPE Technical Conference, Orlando, FL, 1997.

15. Dâra, B. G. Ph.D. Thesis, Middle East Technical University, 2001.

16. Smith, B. Infrared Spectral Interpretation: A Systematic Approach; CRC: Washington, DC, 1999.

17. Holst, G. C. Testing and Evaluation of Infrared Imaging Systems, 2nd ed.; Winterpark: Bellingham, WA, 1998.

18. Stuart, B. Modern Infrared Spectroscopy, Analytical Chemistry by Open Learning; Wiley: Greenwich, England, 1996.

19. Morgan, R. J.; Mones, E. T. J Appl Polym Sci 1987, 33, 999. 